\title{
DESQUALIFICADAS: ASSIM SE EXPLICA A FALTA DE TRABALHO PARA AS PESSOASS COM DEFICIÊNCIA
}

\section{DISQUALIFIED: THERE IS EXPLAINED LACK OF WORK FOR PEOPLE WITH DISABILITIES}

\author{
Josemar Figueiredo Araújo ${ }^{1}$
}

\section{Resumo}

Questionando se a falta de qualificação das pessoas deficientes é motivo relevante para o forte desemprego existente neste grupo social, verificamos que as oportunidades de trabalho para as pessoas com deficiência são escassas, o que pode ser explicado por diversas razões, a mais frequente é a falta de qualificação. Questionamos este argumento, uma vez que existe forte desemprego entre deficientes que apresentam qualificações profissionais.

Palavras Chave: pessoas com deficiência, lei de cotas, qualificação, emprego, empresas privadas.

\begin{abstract}
Questioning whether the lack of qualification of disabled people is a relevant reason for the strong unemployment in this social group, we find that the job opportunities for people with disabilities are scarce, which can be explained by several reasons and the most frequent is the lack of qualification. We question this argument, since there is strong unemployment among disabled people with professional qualifications.
\end{abstract}

Keywords: people with disabilities, quota law, qualification, employment, private companies.

\footnotetext{
${ }^{1}$ Doutor em Sociologia do Direito pela Universidade Federal Fluminense (UFF); professor das Univercidades Veiga de Almeida (UVA) e EStácio de Sá (UNESA).
} 


\section{Introdução}

No Brasil, as pessoas com deficiência, têm assegurada uma reserva legal de $2 \%$ a $5 \%$ das vagas disponíveis nas empresas privadas com 100 ou mais empregados. A garantia legal não impede que indivíduos com deficiência, em sua grande maioria, vivam do desemprego, da informalidade e até mesmo do benefício de um salário mínimo que o Estado concede aos deficientes que não podem prover sua própria subsistência ou tê-la provida por sua família.

As oportunidades de trabalho para as pessoas com deficiência são sempre cercadas de estereótipos, que assumem status de verdade e terminam por constituírem-se como barreiras à consecução destas oportunidades. Um deles está na repetida afirmação de que "pessoas com algum tipo de deficiência desenvolvem outras habilidades para compensar certas limitações”. Presume-se, por ela, que todas as pessoas são iguais ao reagirem às suas próprias incapacidades, o que não necessariamente acontece com todas as pessoas com deficiência, os seres humanos são diferentes e não reagem igualmente aos fatos da vida. Ainda que este clichê tenha uma aparente lógica, não há quaisquer estudos científicos que afirmem ser este fato uma realidade comum a todos os deficientes.

A eficiência e a deficiência são frequentemente utilizadas em um jogo de palavras, como base de um argumento que tenta demonstrar o quão produtivas podem ser pessoas com limitações. Esta modalidade de argumentação instrumentalizada por jogos de palavras, apesar de soar bem, mostra-se pouco útil ao papel que se destina. Constituem-se vários chavões que vão se somando. Eficiência e deficiência não guardam a relação diretamente proporcional que se costuma propagar, da mesma forma que a falta de deficiência não pressupõe maiores habilidades. Um advogado cego, em comparação com um outro profissional sem deficiência na mesma atividade, pode ser menos, mais ou tão eficiente quanto seu colega de profissão, sem que isto guarde relação com a deficiência ou a falta dela.

Este trabalho pretende analisar o argumento segundo o qual "as empresas não cumprem a Lei de Cotas porque as pessoas com deficiência não estão qualificadas para o mercado". Ou ainda, de que a exigência de contratação de deficientes fere o direito das empresas de contratarem livremente seus trabalhadores segundo suas necessidades de 
qualificação. Estes argumentos, parecem ter se transformado em um "mantra", vem sendo utilizados indiscriminadamente nas mais variadas ocasiões para justificar a negativa, por parte das empresas, de oportunidades formalmente garantidas. Para a análise pretendida, partiremos da exposição do comando legal, educação, passando pela dificuldade de preenchimento das cotas, chegando à argumentação central. Metodologicamente, a pesquisa ocupou-se da análise da legislação relativa ao tema, comparando-a com a realidade informada por dados estatísticos oficiais e com a literatura dedicada ao tema.

\section{O comando legal}

Por determinação contida nos Arts. 93 da Lei 8213 de 1990, e 36 do Decreto Federal 3.298 de 1999, a empresa com 100 ou mais empregados está obrigada a preencher de $2 \%$ a 5\% dos seus cargos com beneficiários reabilitados ou pessoas com deficiência, observando-se que aquelas com até 200 empregados devem preencher 2\% das vagas; as empresas que têm de 201 a 500 devem preencher 3\%; as que têm de 501 a 1.000 devem preencher $4 \%$; já as empresas com 1.001 ou mais empregados estão obrigadas a preencher a cota máxima de 5\%. Por tratar-se de norma trabalhista, deve-se observar que o conceito de empresa da Lei 8.213 de 1991 é o mesmo contido na Consolidação das Leis do Trabalho, obrigando, assim, tanto as empresas com fins lucrativos quanto as que não possuem tais escopos.

O Ministério do Trabalho e Emprego, por meio da Instrução Normativa número 20, de 2001, estabelece que, para efeito de aferição dos percentuais estipulados pelo artigo 93 da Lei 8213 de 91, deve ser considerado o número de empregados da totalidade dos estabelecimentos da empresa, sem que haja necessidade de distribuição dos cargos destinados aos empregados com deficiência por seus estabelecimentos, isto é, podem ditos trabalhadores estar centralizados ou distribuídos pelas diversas unidades.

Já as frações de unidade, para efeito do cálculo das cotas, devem ser interpretadas em benefício da contratação de pessoas com deficiência. Isto significa que, se determinada empresa conta com 260 empregados, está obrigada a contratar 3\% de trabalhadores com deficiência, o que equivale a 7,8\%, então, deve contratar 8 empregados, elevando este fracionamento a uma vaga.

Ainda por força do mesmo dispositivo legal, tanto a dispensa de trabalhador reabilitado ou de deficiente habilitado ao final de contrato por prazo determinado de mais de 90 dias, quanto a decorrente de contrato por prazo indeterminado, só poderão ocorrer após a 
contratação de substituto em condição semelhante. Assim, as únicas situações em que o empregador pode dispensar o trabalhador com deficiência e substituí-lo por outro sem deficiência ocorrem quando a empresa não está obrigada ao preenchimento da cota mínima (tem 80 empregados, por exemplo), ou quando conta com número de empregados com deficiência superior ao limite mínimo exigido por lei. É o caso da empresa com 100 empregados, dos quais 5 têm deficiência. Como o mínimo de empregados com deficiência deve ser igual a 2, a empresa, conforme o exemplo, pode dispensar até 3 empregados com deficiência e substituí-los por outros que não possuam quaisquer limitações.

As penalidades aplicáveis para as situações em que há descumprimento das prescrições contidas no Art. 93 da Lei 8213 de 1991 estão disciplinadas no Art. 133 do mesmo conjunto legal e nos artigos 10 e 15 da Instrução normativa número 20 de 2001. Com base no primeiro dispositivo mencionado, a empresa que, sujeita às cotas, não promove seu correto preenchimento, está sob pena do pagamento de multa, nos termos do que estabelece a portaria número 1.199 de 28 de outubro de 2003 do Ministério do Trabalho e Emprego.

Para as empresas que têm de 100 a 200 empregados, calcula-se a multa multiplicando-se o número de cargos que deixaram de ser preenchidos por trabalhadores com deficiência ou reabilitados, pelo valor mínimo acrescido de 0 a 20\%; para empresas que têm de 201 a 500 empregados, multiplica-se o número de cargos que deixaram de ser preenchidos por trabalhadores com deficiência ou beneficiários reabilitados pelo valor mínimo acrescido de 20 a 30\%. As empresas que têm de 501 a 1000 empregados são multadas, multiplicando-se o número de cargos que deixaram de ser preenchidos por trabalhadores com deficiência ou beneficiários reabilitados pelo valor mínimo acrescida de $30 \%$ a $40 \%$; e, finalmente, as empresas que contam com mais de 1001 empregados recebem a referida penalidade, após a multiplicação do número de cargos que deixaram de ser preenchidos por trabalhadores com deficiência ou beneficiários reabilitados pelo valor mínimo legal acrescido de 40 a $50 \%$. Este valor mínimo legal a que nos referimos tem previsão no já mencionado Art. 133 da Lei 8213 de 1991 e é, anualmente, corrigido pela portaria interministerial dos Ministérios da Fazenda e da Previdência Social que reajusta os benefícios mantidos por esta última.

Estes parâmetros de cálculo devem observar os limites mínimo e máximo, não podendo as multas aplicadas corresponderem a valores que estejam fora destes limites. Para exemplificar o cálculo da multa, vamos recorrer aos valores estipulados na portaria interministerial MPS/MF $\mathrm{n}^{\circ}$ 48, de 12 de fevereiro de 2009, cujo valor mínimo encontra-se 
fixado em $\mathrm{R} \$ 1.329,18$ e o máximo em $\mathrm{R} \$ 132.916,84$. Uma empresa que conta com um quadro de 3.000 empregados está obrigada a preencher 150 cargos por trabalhadores com deficiência ou reabilitados. Admitindo, também por hipótese, que ela só mantenha em seus quadros 70 pessoas em ditas condições, terá deixado de preencher 80 vagas. Na aplicação da multa, toma-se o valor mínimo legal de R \$ 1.329,18, acrescendo-lhe o mínimo de 40\%, chegamos à quantia de $\mathrm{R} \$ 1.860,85$ que deverá ser multiplicada por 80 , atingindo-se a importância de $\mathrm{R} \$ 148.868,16$, porém, como o limite máximo é de $\mathrm{R} \$ 132.916,84$, a penalidade será fixada neste patamar. Para os casos de dispensa de empregados com deficiência ou beneficiários reabilitados sem a prévia contratação de outros, procede-se da mesma maneira. Vejamos a tabela abaixo:

\begin{tabular}{|c|c|c|c|c|}
\hline Quadro geral & Mínimo legal & Mínimo por vaga & Máximo por vaga & Teto \\
\hline de 100 a 200 & $\mathrm{R} \$ 1.329,18$ & $\mathrm{R} \$ 1.329,18$ & $\mathrm{R} \$ 1.595,02$ & $\mathrm{R} \$ 132.916,84$ \\
\hline de 201 a 500 & $\mathrm{R} \$ 1.329,18$ & $\mathrm{R} \$ 1.595,02$ & $\mathrm{R} \$ 1.727,93$ & $\mathrm{R} \$ 132.916,84$ \\
\hline de 501 a 1.000 & $\mathrm{R} \$ 1.329,18$ & $\mathrm{R} \$ 1.727,93$ & $\mathrm{R} \$ 1.860,85$ & $\mathrm{R} \$ 132.916,84$ \\
\hline mais de 1.000 & $\mathrm{R} \$ 1.329,18$ & $\mathrm{R} \$ 1.860,85$ & $\mathrm{R} \$ 1.993,77$ & $\mathrm{R} \$ 132.916,84$ \\
\hline
\end{tabular}

Relativamente às penas contidas nos Arts. 13, 14 e 15 da Resolução número 20 de 2001 do Ministério do Trabalho e Emprego, se, mesmo após a ação fiscal, não se verificar a regularização do preenchimento das vagas, podem ser adotados vários procedimentos administrativos, dentre os quais, a intervenção do Núcleo de Promoção da Igualdade de Oportunidades e Combate à Discriminação; celebração de Termo de Compromisso, contendo o cronograma de preenchimento das vagas das pessoas com deficiência ou beneficiários reabilitados de forma gradativa constando, também, a obrigatoriedade da adequação das condições dos ambientes de trabalho; e não havendo, ainda assim, o regular preenchimento, procede-se ao encaminhamento de relatório circunstanciado ao Delegado Regional do Trabalho para remessa ao Ministério Público do Trabalho.

Percebe-se que todas estas garantias legais não coíbem práticas, como as de se alocar todos os trabalhadores com deficiência em um único setor da empresa, ou o recrutamento de trabalhadores com as deficiências mais leves, em detrimento daqueles com maiores limitações.

\section{A dificuldade de preenchimento das cotas}


Um dos argumentos mais comuns para justificar o baixo índice de cumprimento das cotas destinadas às pessoas com deficiência consiste em dizer-se que nem toda empresa precisa contratar; assim, para preencher as cotas, teriam de demitir trabalhadores já integrados e conhecedores da empresa. O segundo argumento está em afirmar-se que as cotas são muito elevadas. E o terceiro, em sustentar que não há bancos de dados aos quais as empresas possam recorrer para encontrar pessoas com deficiência qualificadas.

O primeiro argumento considera que não se pode presumir, de modo absoluto, que toda empresa precisa contratar. Pastore (2000) lembra que, se uma empresa está com o quadro de funcionários completo, ela precisaria demitir empregados sem deficiência para contratar pessoas com limitações. Evidentemente que isto geraria um conflito entre os empregados da empresa e os candidatos deficientes.

Nesse conflito, a empresa ficaria de fora, podendo alegar, simplesmente, não querer prejudicar empregados antigos e bem entrosados em favor de novos que ela não conhece. Estariam as autoridades dispostas a assumir o ônus da dispensa para a empresa contratar portadores de deficiência em vagas que não existem? (p. 185)

A análise faz todo sentido, porém o processo de implantação das cotas não é algo feito em dias ou semanas, trata-se de um procedimento longo que se faz à medida que a empresa demite e contrata. Não é objetivo da política social a substituição de pessoas sem deficiência por pessoas com deficiência. Todavia faz parte da rotina das empresas a substituição de empregados, seja por morte, por aposentadoria, por dispensa, por promoção, entre outras, ou seja, é neste contexto que as cotas devem ser implementadas.

O pior dos mundos seria uma política social que fizesse a discriminação ao revés, isto é, obrigando a demissão de não deficiente para a contratação de pessoas com deficiência, isto não seria política social, mas ao contrário, política discriminatória que faria a inclusão de uns através da exclusão de outros.

Quanto ao fato de serem elevadas, há que se analisarem os dados indicadores de que o Brasil, até 2008, não havia conseguido preencher sequer $20 \%$ do total das vagas que deveriam ser destinadas às pessoas com limitações. As cotas estipuladas no Art. 93 da Lei 8213 de 1991 chegam, no máximo, a 5\% do total de empregados da empresa. Ao mesmo 
tempo o censo demográfico $2000^{2}$ mostra que havia, naquele ano, 15.979.021 deficiências em homens, 18.601.700 deficiências em mulheres e um total de 34.580.721. O total de pessoas com deficiência era de 24.600.256, sendo 11.420 .544 homens e 13.179 .712 mulheres $^{3}$. Os dados sobre a quantidade de pessoas com deficiência em condições de trabalhar são controvertidos, até porque o próprio número de pessoas com deficiência, no Brasil é bastante questionado. Então, vamos admitir, por hipótese, o número fornecido pelo próprio Ministério do Trabalho e Emprego, dando conta de que há, no Brasil, 9 milhões de pessoas com deficiência em idade de trabalhar. A Relação Anual de Informações Sociais (RAIS) de 2016 mostra que deveriam existir, aproximadamente, 820 mil vagas, caso todas as empresas conseguissem adequar-se à Lei de Cotas, considerando-se esta informação nem $10 \%$ do total de pessoas com deficiência em idade de trabalhar estavam empregadas em 2007.

A Relação Anual de Informações Sociais (RAIS) divulgada em agosto de 2017 com dados de 2016 revelou a existência de 46.060.mil trabalhadores formais, o que revela um crescimento de 3,8\% em relação ao ano de 2015, mantendo-se o percentual de contratação formal das pessoas com deficiência abaixo de $1 \%$. Dado a considerarmos é a subida do percentual de pessoas com deficiência empregadas, em um período em que o total de vínculos formais caiu significativamente. Ainda que o número de trabalhadores com deficiência tenha mais que dobrado em 10 anos, passando de 126 mil em 2007 para 418,5 mil vínculos em 2016, em termos percentuais, pessoas com deficiência não representam sequer $1 \%$ dos trabalhadores formais, apesar de representarem, segundo o Censo 2010, 24\% da população. O número de trabalhadores com deficiência formalmente empregados, se comparados aos 9 milhões de trabalhadores com deficiência em idade de trabalhar, (IBGE 2010) mostra o tamanho da exclusão no mercado de trabalho. Por outro lado, não há dados suficientes a permitirem a afirmação segundo a qual os baixos índices de cumprimento da Lei de Cotas decorrem da falta de qualificação dos beneficiários da dita norma.

A conclusão não pode ser outra: reduzir as cotas significa resolver o problema das empresas que não logram preenchê-las e agravar a exclusão das pessoas com deficiência do

\footnotetext{
2 O Centro de Documentação e Informação da Pessoa Portadora de Deficiência (CEDIPOD) questiona os dados do censo, ressaltando que os indicadores da OMS, informam que, nos países desenvolvidos, $10 \%$ da população possui algum tipo de deficiência. Em contraposição, o sítio eletrônico do Census, do governo americano mostra que no censo de 1995 foram encontradas $20 \%$ de pessoas com algum tipo de deficiência. Por estas razões, com o histórico de pobreza, desnutrição e falta de prevenção, não há, segundo o CEDIPOD como acreditar que no Brasil este percentual é menor.

${ }^{3}$ Considerando-se a múltipla deficiência, o número de deficiências tende a ser maior que o de deficientes.
} 
mercado formal de trabalho, logo, se há dificuldades no preenchimento das cotas, tendo-se por base os dados oficiais, não há como atribuir estas ao fato de serem elevadas. Mais elevado que as cotas é o déficit entre o número de pessoas efetivamente contratadas (323 mil e 200) e o número de pessoas com deficiência em idade de trabalhar (aproximadamente 9 milhões).

A crítica relativa à ausência de banco de dados com informações sobre trabalhadores com deficiência vem sendo levada em conta pelo Poder Legislativo. O projeto de Lei 3584/2008 4 , que tramita na Câmara dos Deputados Federais prevê a possibilidade de que o Ministério Público do Trabalho e as entidades sem fins lucrativos, que tenham por finalidade a assistência às pessoas com deficiência, possam criar banco de dados com o objetivo de facilitar o preenchimento das quotas destinadas às pessoas com deficiência ${ }^{5}$.

Existem entidades não governamentais especializadas em cadastro, treinamento e recrutamento de pessoas com deficiência, muitas delas inscritas em programas subsidiados pelo próprio Ministério do Trabalho e Emprego. Na prática, estes bancos de dados já existem, entretanto o que se busca são portadores de deficiência com experiência, isto é, já qualificados. Em todos os Estados do Brasil, há associações de pessoas com deficiência e a informação digital é de fácil acesso às empresas com 100 ou mais empregados. $\mathrm{O}$ argumento da falta de informação não se sustenta: o próprio Ministério do Trabalho e Emprego, ao conceder prazo às empresas para adequarem-se à Lei de Cotas, as informa sobre as entidades que podem assistir à empresa nos processos de seleção e recrutamento.

Não há qualquer vedação legal à criação de banco de dados pelo Ministério Público do Trabalho, assim como não há por parte das entidades voltadas para a assistência aos portadores de deficiência, se não ha proibição, é permitido, e, na prática isto já vem sendo feito.

\section{A baixa qualificação das pessoas com deficiência}

A mais frequente das manifestações das empresas privadas, obrigadas a incluírem em seus quadros trabalhadores com deficiência, constitui-se na reclamação de que não há número de pessoas com deficiência qualificadas para o adequado preenchimento das vagas a elas

\footnotetext{
${ }^{4}$ Apensado ao Projeto de Lei 3638/2000.

${ }^{5} \mathrm{O}$ projeto, entretanto, vem causando polêmica ao dispor que: "Não será aplicada a multa fixada na lei vigente na hipótese de o não-preenchimento da quota pela empresa resultar comprovadamente da inexistência, nos bancos de dados, de candidato habilitado ao desempenho da função."
} 
destinadas. Em geral, segundo dito pelos departamentos de recursos humanos das empresas, os deficientes que almejam oportunidades de trabalho não têm escolarização, ou quando tem, esta é insuficiente para permitir-lhes o exercício de qualquer função nos cargos das corporações.

Pesa também contra as pessoas com deficiência o fato de, em sua grande maioria, não terem experiências profissionais, outro motivo bastante utilizado para afirmar-se que elas não têm qualificação suficiente para o mercado. Então, o simples fato de não terem qualificação é suficiente para justificar que permaneçam sem emprego, sem renda e sem oportunidades de trabalho.

Profissionais de recursos humanos que atuam no campo da empregabilidade de pessoas com deficiência destacam que a avaliação da qualificação visa a estimar e medir as habilidades, aptidões e as potencialidades. Devem-se verificar as capacidades buscando-se conhecer melhor o seu potencial de trabalho ou as possíveis necessidades de habilitação e reabilitação. Em um outro momento, devem ser verificadas as habilidades do candidato com deficiência para atender às exigências do cargo que a empresa oferece.

A despeito destas recomendações, Pastore (2000, p.184) insiste em apontar a ineficácia do sistema de cotas, descrevendo as resistências oferecidas por parte das empresas, ao que chama de "sistema de cotas isoladas". No dizer deste crítico:

\footnotetext{
O sistema de cotas tem pouca eficiência quando a empresa não quer ou não pode admitir portadores de deficiência. Os mais variados subterfúgios, inclusive legais, são usados para evitar a contratação. Algumas empresas contratam advogados para apresentar argumentos sofisticados que justifiquem a não-contratação. Outras, mais pragmáticas, simplesmente elevam os requisitos de qualificação para o preenchimento da vaga em aberto. Com isso, elas restringem de modo considerável o número de portadores de deficiência que podem se candidatar àquele posto de trabalho. Dentro dessa estratégia, as empresas podem enviar às autoridades do trabalho os perfis ocupacionais desejados, deixando para estas a tarefa de constatar a inexistência de candidatos habilitados para aquelas funções. $\mathrm{O}$ que podem as autoridades fazer para "forçar" as empresas a contratar o que elas não precisam?
}

A falta de qualificação das pessoas com deficiência mostra-se um argumento tão forte quanto refutável. Visando a suprir a falta de informação (não à resistência discriminatória), o Ministério do Trabalho e Emprego (2007) explica que:

A equipe que efetua a seleção deve estar preparada para viabilizar a contratação deste seguimento. Principalmente, precisa ter claro que as exigências a serem feitas devem estar adequadas às peculiaridades que caracterizam as pessoas com 
deficiência. Se isto não ocorrer, vai ser exigido um perfil de candidato sem qualquer tipo de limitação. (p. 23)

A Lei de Cotas foi feita para permitir o acesso ao mercado de trabalho, de um grupo que não tem meios para concorrer em igualdade de condições com os demais. Aumentar as exigências de qualificação ou exigir da pessoa com deficiência habilidades que ela não possui, em decorrência da própria limitação, apesar de ser um expediente comum, é entendido pelas autoridades fiscalizadoras do trabalho como fraude à Lei de Cotas.

Ainda no tocante à falta de experiência, um dos requisitos exigidos por muitas empresas nos processos de contratação, o Ministério do Trabalho e Emprego (2007) lembra o quanto esta exigência pode ser excludente e tornar ainda mais difícil a contratação.

Antes de ser exigida a obrigatoriedade de contratação de pessoas com deficiência, raras eram as empresas que as empregavam. Portanto a elas não foram dadas oportunidades para terem em seu currículo experiência profissional. Assim, de uma forma geral, delas não se deve exigir experiência. (p. 23)

Se a experiência for indispensável, a própria empresa deve dar a oportunidade de aquisição, internamente, dos conhecimentos, habilidades e posturas exigidos, conforme previsto na Recomendação 168 da Organização Internacional do Trabalho ${ }^{6}$.

$\mathrm{O}$ argumento da baixa escolaridade ou da falta dela também não se mostra aceito pelo Ministério do Trabalho e Emprego. Reconhecendo que este fato é uma realidade, o órgão pondera que:

Às pessoas com deficiência também não foram dadas iguais oportunidades de acesso à escolarização. Entretanto, muitas vezes, apesar de não terem a certificação, tiveram acesso ao conhecimento através do apoio da família ou da comunidade local. De outro lado, muitas vezes é exigido, de forma generalizada, um patamar de escolaridade que não é compatível com as exigências de fato para o exercício das funções. (p. 23)

O preconceito contra pessoas com limitações está, muitas vezes, oculto, mas inteiramente instalado em negativas de contratações que têm por justificativa a falta de qualificação das pessoas. Resistir e rejeitar às diferenças também é uma característica das empresas. Vejamos o caso dos empregados que, até serem acometidos por acidentes, doenças ocupacionais que trazem como consequência certo nível de incapacidade, são tidos por bons e

\footnotetext{
${ }^{6}$ Devemos lembrar que este expediente de alegar falta de experiência para não contratar também afeta os jovens de maneira geral à procura do primeiro emprego.
} 
bem qualificados. Por razões que as empresas não explicam, é muito comum a dispensa de empregados que passam por afastamento temporário e retornam na condição de reabilitados. Por que são demitidos? Desaprenderam ou deixaram de conhecer a empresa? ${ }^{7}$

A própria RAIS 2008, mostra que na situação de reabilitados foram declarados $11,78 \%$ dos deficientes com vínculo trabalhista, o que leva à conclusão de que os empregados reabilitados não poderiam representar tão pouco, uma vez que não desaprendem em razão de acidentes de trabalho ou doenças ocupacionais e ainda que percam parte da capacidade laboral, em sua grande maioria, são capazes de exercer outras funções inclusive pelo conhecimento que têm da empresa.

Argumentar sobre a falta de qualificação das pessoas com deficiência tornou-se a maneira mais comum entre as empresas de justificar a falta de contratação. A garantia aos portadores de deficiência de tentarem exercer as funções dos cargos disponíveis, que seria a forma prática de demonstrar as capacidades e habilidades ou de confirmar a falta de qualificação, só vem sendo conseguida após o surgimento da Lei de Cotas e da maior ênfase dada à fiscalização.

Em outras palavras, as empresas, por diversas razões, ao tomarem o serviço das pessoas, permitem que elas sofram acidentes ou sejam acometidas por doenças ocupacionais e, posteriormente, recusam-se a permanecer com os serviços do reabilitado. São estas mesmas empresas que desejam mais estímulos econômicos para manter, em seus quadros, pessoas a quem muitas vezes elas mesmas causaram a deficiência.

Nestes sentido, a situação das pessoas com algum tipo de limitação em relação às empresas que resistem ao processo de contratação, previsto na Lei de Cotas, parece exigir, primordialmente, fiscalização e punição, afinal, como esperar de empresas que discriminam reabilitados de acidentes e doenças sofridas sob sua própria subordinação venham a contratar

\footnotetext{
${ }^{7}$ Para exemplificar esta prática utilizamos reportagem no sítio eletrônico Consultor Jurídico relatando os casos das empresas Garoto e Sebrae. No caso da Empresa Garoto, a trabalhadora foi admitida sem quaisquer limitações, deficiência ou problemas de saúde, no mês de setembro de 1990. Já no mês de maio do ano de 1993, estava com sintomas de Lesão por Esforço Repetitivo (LER). Sete anos depois, sofreu acidente de trabalho, que a deixou com lesões permanentes no joelho e no braço. As dores resultaram em intervenção cirúrgica. Ao retornar ao trabalho, a empregada foi dispensada. A funcionária alegou, segundo a reportagem, que, por ser portadora de LER e ter sido reabilitada pelo INSS, não poderia ter sido dispensada. Foi pedida à Justiça do Trabalho a reintegração em função compatível com sua capacidade física e as verbas trabalhistas de direito. Seu pedido foi atendido por todas as instâncias com fundamento no viés protetivo da Lei 8213 de 1991.

O caso do Sebrae é semelhante. A Justiça do Trabalho determinou a reintegração, pois a empresa não comprovou ter contratado outro trabalhador reabilitado para o seu posto, sendo, portanto, nula a dispensa. O relator do recurso na $6^{\mathrm{a}}$ Turma do TST, ministro Aloysio Corrêa da Veiga, adotou fundamentos semelhantes aos da decisão da $4^{\mathrm{a}}$ Turma e lembrou que a inobservância na manutenção das cotas gera o direito do empregado demitido à reintegração. (CONSULTOR JURÍDICO, 17 de setembro de 2008).
} 
portadores de deficiência habilitados? Quando a não contratação decorre de opções fundadas em argumentos discriminatórios, os estímulos econômicos defendidos como forma de resolver o problema podem desestimular as empresas que já se decidiram por preencher suas cotas. Estimular a quem descumpre é incentivar quem está cumprindo a passar a descumprir.

Há quem defenda que várias empresas não contratam por falta de informação, porém, na sociedade pós-moderna, a desinformação não precisa fazer parte da rotina de empresas com recursos suficientes para terem acesso a todos os dados relativos às pessoas com deficiência, suas habilidades, capacidades, saúde e direitos. Empresas com 100 ou mais empregados, por seu próprio tamanho, podem solicitar e pagar por informações jurídicas, médicas, pedagógicas, entre outras. Portanto, o argumento da desinformação é contraditório com o próprio tamanho e poder econômico destas empresas.

$\mathrm{Na}$ vida prática, o que as pessoas com deficiência têm encontrado são grandes dificuldades na conquista de um emprego. Qualificadas ou não, estas dificuldades existem e não são poucas. Os defensores do argumento da falta de qualificação como causa do desemprego entre as pessoas com deficiência mostra o quanto eles não sabem o que elas realmente vivem ao buscarem oportunidades. Condenado ou não a desaparecer, o emprego formal tal qual previsto na CLT é o mais procurado por deficientes e não deficientes. Nesta busca os preconceitos são sentidos com toda a sua força.

Sair de casa para procurar um emprego não é uma das tarefas mais fáceis para pessoas com deficiência. Se elas, muitas vezes, não precisam ter dinheiro para pagar o transporte, precisam, por outro lado, contar com conduções acessíveis, apoio de outras pessoas em travessias de ruas, prédios que lhes permitam chegar às agências de emprego e aos setores de recursos humanos das empresas. Dito de outra maneira, as pessoas com deficiência, além das dificuldades já conhecidas para encontrar um emprego, também enfrentam aquelas correlatas à própria natureza das limitações que possuem.

O Jornal Folha de São Paulo, em reportagem relativamente recente, mostrou que inclusive pessoas com deficiência que possuem diploma de curso superior enfrentam várias dificuldades, mencionando, como exemplos, a falta de acessibilidade, atribuição de funções aquém das habilidades do deficiente, e desrespeito. Descrevendo o despreparo e o preconceito suportado pelas pessoas com deficiência que buscam um emprego, a reportagem relata:

A biblioteconomista Helena Maranhão, 27, que teve paralisia cerebral e fala e se movimenta com dificuldade, diz ter sido isolada do público em seu último emprego, 
em uma biblioteca de São Paulo. Lá, onde trabalhou por três meses, a carteira de trabalho registrava "auxiliar de serviços gerais". Mesmo desempenhando uma função mais qualificada - Maranhão fazia pesquisa para novas aquisições -, a profissional conta que teve de ficar em uma sala fechada. "Se a empresa tivesse preparo, eu estaria no balcão, em contato com os usuários." Moradora do Itaim Bibi (zona oeste), Maranhão tem acesso a tratamento médico e a um acompanhante para voltar para casa depois do serviço. Mas, na empresa em que trabalhou e de que foi demitida por "não atender às expectativas", ela não tinha acesso a um teclado especial, o que agilizaria seu trabalho. Apesar de concorrer a vagas reservadas a deficientes, a profissional recebe ligações que mostram o despreparo de recrutadores. "Perguntam se estou bêbada. Nunca pensam que é a minha voz normal", diz. (Folha de S.Paulo 17 de agosto de 2008).

Muitas empresas fazem do discurso da qualificação uma cortina que esconde seus próprios preconceitos. Vários estudiosos vêm comprando esta ideia como uma verdade absoluta, porém, é preciso questionar este argumento. É cientificamente saudável investigar o que acontece com os profissionais deficientes qualificados. A afirmação segundo a qual "os deficientes qualificados não estão disponíveis no mercado", decantada rotineiramente, precisa ser questionada. Enquanto profissionais de recursos humanos e empresas transformam frases feitas em dogmas, as organizações voltadas para pessoas com deficiências tentam impor a lei a qualquer preço e os deficientes penam, com suas bengalas, cadeiras de rodas, muletas etc pelas instituições em busca de trabalho.

Fernanda Bucci, 25, cursou psicologia até o segundo ano na Unip (Universidade Paulista). Moradora de Perdizes (Zona Oeste), fala e se locomove com dificuldade, devido à falta de oxigenação que sofreu no momento do parto. A profissional ressalta que pode assumir muitas funções, mas, para isso, precisa de um mínimo de acessibilidade. Ela conta já ter ido a mais de 20 entrevistas de emprego desde que saiu da empresa do pai, em 2007. Mesmo lá, sendo filha do dono, conta que o preconceito era grande. "Tinha dificuldade para que cumprissem as minhas ordens", afirma. Outros profissionais relatam que, mesmo quando conseguem uma vaga, são alocados em funções que estão aquém da sua qualificação. (Folha de S.Paulo, 17 de agosto de 2008).

A qualificação profissional das pessoas com deficiência, assim como o comando legal que reserva vagas são apenas dois componentes importantes capazes de fazer diferença na busca de oportunidades de emprego pelos deficientes, entretanto, esta caminhada é muito mais complexa, envolve preconceitos, estigmas, intolerância, despreparo, autoestima dos próprios portadores de deficiência e tantos outros fatores que o determinismo da falta de qualificação vem escondendo.

\section{Conclusão}


Em um estudo mais aprofundado, percebemos a existência de empresas que simplesmente ignoram a Lei de Cotas e não a cumprem, preferindo esperar medidas de repressão estatal e atuarem juridicamente na defesa de argumentos contra a obrigatoriedade da contratação. Outras empresas contratam pura e simplesmente para cumprir a Lei, dando preferência às deficiências mais leves para as quais não se fazem necessárias adaptações ou os custos para ditas adequações são muito baixos, trata-se de empresas que procuram a deficiência e não a pessoa. Por fim, há as empresas socialmente responsáveis, que tem o discurso segundo o qual a qualificação das pessoas com deficiência também é responsabilidade da empresa. Assim, elas contratam, qualificam e empregam.

Aquelas corporações que ignoram a lei precisam da fiscalização. As empresas que tratam a Lei de Cotas como um problema e contratam apenas para cumpri-la devem receber informação, apoio e incentivos para melhorar as condições de trabalho de seus trabalhadores com deficiência, tornando a convivência mais harmônica e produtiva. Já as empresas que transformaram a colocação profissional das pessoas com deficiência em um dos objetivos de sua política social, devem receber estímulos, inclusive para a contratação de pessoas com deficiências mais severas.

O próprio comprometimento de uma parte das empresas em cumprir a legislação com responsabilidade social mostra uma mudança de paradigma. Abandona-se a ideia de que a qualificação profissional deve ser buscada pelo portador de deficiência e fornecida apenas pelo Estado e parte-se para a atuação empresarial neste campo.

Tudo aqui escrito tem por finalidade reconhecer que a falta de qualificação das pessoas com deficiência gera desemprego entre elas, porém não é menos verdade que há poucos estudos sobre a sorte das pessoas com deficiência que estudaram e qualificaram-se. Aliás, pessoas que adquirem deficiências, depois de completado seu processo de formação profissional e reabilitam-se, sofrem com demissões e com as mesmas dificuldades que as pessoas com deficiência habilitadas. Por outras palavras, é necessário, antes de atribuir-se o desemprego das pessoas com deficiência apenas à falta de qualificação, observar-se o que ocorre com os deficientes profissionalmente qualificados.

O discurso puramente econômico e a crítica à Lei de Cotas, que afirmam ser impossível manter na empresa empregados improdutivos, tem, como contraponto, corporações oferecendo várias oportunidades de o empregado com deficiência ser produtivo. 
Não é que as empresas renunciem à boa produtividade, parece mesmo que elas pretendem aumentar a produtividade do portador de deficiência atribuindo-lhes outras funções, oferecendo a oportunidade de que tentem atuar em outras atividades.

Após tudo isto, dos próprios discursos das empresas e da realidade encontrada, infere-se que a finalidade principal é cumprir a Lei de Cotas. Mas, se há uma política empresarial que contempla a qualificação das pessoas com deficiência pelas próprias corporações, se há preocupações em não discriminar, em valorizar a diversidade, isto também tem como causa uma política social desenvolvida pelo Estado através da própria legislação. Esta mudança de paradigma só veio a se efetivar após o surgimento da Lei de Cotas. Se ela não resolve todos os problemas, estes progressos não se devem ao acaso ou às coincidências e só vieram após sua efetiva regulamentação. 


\section{Referências}

BRASIL. DECRETO No 3.048, DE 6 DE MAIO DE 1999. Aprova o Regulamento da Previdência Social, e dá outras providências.

BRASIL. DECRETO No 3.298, DE 20 DE DEZEMBRO DE 1999. Regulamenta a Lei no 7.853 , de 24 de outubro de 1989, dispõe sobre a Política Nacional para a Integração da Pessoa Portadora de Deficiência, consolida as normas de proteção, e dá outras providências.

BRASIL. DECRETO No 3.956, DE 8 DE OUTUBRO DE 2001. Promulga a Convenção Interamericana para a Eliminação de Todas as Formas de Discriminação contra as Pessoas Portadoras de Deficiência.

BRASIL. DECRETO LEGISLATIVO No 186, DE 09 DE JULHO DE 2008. Aprova o texto da Convenção sobre os Direitos das Pessoas com Deficiência e de seu Protocolo Facultativo, assinados em Nova Iorque, em 30 de março de 2007.

BRASIL. LEI 7.853, DE 24 DE OUTUBRO DE 1989. Dispõe sobre o apoio às pessoas portadoras de deficiência, sua integração social, sobre a Coordenadoria Nacional para Integração da Pessoa Portadora de Deficiência - Corde, institui a tutela jurisdicional de interesses coletivos ou difusos dessas pessoas, disciplina a atuação do Ministério Público, define crimes, e dá outras providências.

BRASIL. LEI No 8.213, DE 24 DE JULHO DE 1991. Dispõe sobre os Planos de Benefícios da Previdência Social e dá outras providências.

CLEMENTE, Carlos Aparício. Trabalho Decente para a Pessoa com Deficiência: Leis, Mitos e Práticas de Inclusão. Osasco: Espaço Cidadania, 2008.

CLEMENTE, Carlos Aparício. Trabalho e Inclusão Social de Portadores de Deficiência. Osasco: Espaço da Cidadania, 2003.

CONSULTOR JURÍDICO. Garoto e SEBRAE têm de reintegrar funcionárias reabilitadas. Consultor Jurídico on-line. São Paulo, 17 set. 2008. Disponível em: <http://www.conjur.com.br/2008-set-17/funcionarias_reabilitadas_reintegradas. > Acesso em: 25 ago. 2009.

FOLHA DE S. PAULO. Qualificados, deficientes relatam dificuldades. Folha on-line. São Paulo, 17 ago. 2008.2 Disponível em: <http://www1.folha.uol.com.br/folha/classificados/empregos/ult1671u434500.shtml> Acesso em: 5 fev. 2009.

FONSECA, Ricardo Tadeu Marques da. O Trabalho da Pessoa com Deficiência e a Lapidação dos Direitos Humanos: O Direito do Trabalho, Uma Ação Afirmativa. São Paulo, LTR/LIDA, 2006.

INSTITUTO BRASILEIRO DE GEOGRAFIA E ESTATÍSTICA. Censo Demográfico 2000: Características da População e dos Domicílios: Resultados do universo. Disponível em 
<http://www.ibge.gov.br/home/estatistica/populacao/default_censo_2000.shtm> acesso em 11 out. 2008.

INSTITUTO ETHOS. $\mathrm{O}$ que é responsabilidade Social. Disponível em: <http://www1.ethos.org.br/EthosWeb/pt/29/o_que_e_rse/o_que_e_rse.aspx> acesso em 16 jun. 2009.

MINISTÉRIO DA EDUCAÇÃO E INSTITUTO NACIONAL DE ESTUDOS E PESQUISAS EDUCACIONAIS ANÍSIO TEIXEIRA. Censo Escolar da Educação Básica 2008. Disponível em: <http://www.inep.gov.br/censo/escolar/DOU_final_2008.htm> acesso em 13 ago. 2009.

MINISTÉRIO DA PREVIDÊNCIA SOCIAL E MINISTÉRIO DA FAZENDA. PORTARIA INTERMINISTERIAL MPS/MF No 48, DE 12 DE FEVEREIRO DE 2009. Dispõe sobre o reajuste dos benefícios pagos pelo Instituto Nacional do Seguro Social - INSS e dos demais valores constantes do Regulamento da Previdência Social e dá outras providências.

MINISTÉRIO DA PREVIDÊNCIA SOCIAL E MINISTÉRIO DO TRABALHO E EMPREGO. Anuário Estatístico de Acidentes do Trabalho 2007. disponível em: <http://www.previdenciasocial.gov.br/conteudoDinamico.php?id=634> acesso em 17 set. 2008.

MINISTÉRIO DO TRABALHO E EMPREGO. Anuário Estatístico da Relação Anual das Informações Sociais (RAIS) 2007. Disponível em: <http://anuariorais.caged.gov.br> Acesso em 17 abr. 2009.

MINISTÉRIO DO TRABALHO E EMPREGO. Anuário Estatístico da Relação Anual das Informações Sociais (RAIS) 2008. Disponível em: <http://anuariorais.caged.gov.br> Acesso em 30 nov. 2009.

MINISTÉRIO DO TRABALHO E EMPREGO. Características do Emprego Formal segundo a Relação Anual de Informações Sociais - 2016 - RAIS 2016. Disponível em <http://www.mte.gov.br/rais/2016/arquivos/Resultados_Definitivos.pdf>. Acesso 25 nov. 2017.

MINISTÉRIO DO TRABALHO E EMPREGO. A Inclusão das Pessoas com Deficiência no Mercado de Trabalho. Brasília: Secretaria de Inspeção do Trabalho, 2007.

MINISTÉRIO DO TRABALHO E EMPREGO. PORTARIA No 1199, DE 28 DE OUTUBRO DE 2003. Aprova normas para a imposição da multa administrativa variável prevista no art. 133 da Lei ${ }^{\circ}$ 8.213, de 24 de julho de 1991, pela infração ao art. 93 da mesma Lei, que determina às empresas o preenchimento de cargos com pessoas portadoras de deficiência ou beneficiários reabilitados.

PASTORE, José. Oportunidades de Trabalho para Deficientes. São Paulo: LTR, 2000.

PINSKY, Jaime. (Organizador). Doze Faces do Preconceito. São Paulo, Editora Contexto, 2000 . 
SECRETARIA DE INSPEÇÃO DO TRABALHO. INSTRUÇÃO NORMATIVA No 20, DE 19 DE JANEIRO DE 2001. Dispõe sobre procedimentos a serem adotados pela Fiscalização do Trabalho no exercício da atividade de fiscalização do trabalho das pessoas portadoras de deficiência.

SECRETARIA DE INSPEÇÃO DO TRABALHO. INSTRUÇÃO NORMATIVA No 36, DE 05 DE MAIO DE 2003. Altera a Instrução Normativa $n^{\circ}$ 20, publicada no Diário Oficial da União de 29.01.2001, Seção 1 página 19 e 20 de 19 de janeiro de 2001, que trata da fiscalização do trabalho das pessoas portadoras de deficiência. 